\title{
Determinação da frequência de anticorpos ABO e RH maternos em recém-nascidos*
}

\section{Determination of the frequency of maternal $A B O$ and $R H$ antibodies in newborns}

Gabriela Muller Reche' Milton Rego de Paula Junior ${ }^{2}$

\section{Resumo}

A Doença Hemolítica do Recém-Nascido (DHRN) é uma anemia hemolítica, causada por incompatibilidade sanguínea materno-fetal que pode ser decorrente da aloimunização por diversos sistemas sanguíneos. Os principais causadores são os sistemas $\mathrm{ABO}$ e Rh. Nesta pesquisa, foi realizado um estudo retrospectivo de análise de 3.080 prontuários de recém-nascidos atendidos pela Hemoclínica de janeiro a junho de 2013. Os resultados demonstraram que 4,83\% dos recém-nascidos tinham positividade no Teste de Antiglobulina Direta e, destes, 2,68\% positivaram, na Pesquisa de Anticorpos, Irregulares. Desse total, 75,33\% dos casos eram relacionados ao sistema $\mathrm{ABO}$ e $6,67 \%$ ao sistema $\mathrm{Rh}$. Foi encontrada uma associação entre os sistemas $\mathrm{ABO}$ e Rh e um antiFya Apesar do avanço nas técnicas de detecção de aloanticorpos e da imunoprofilaxia ter levado ao decréscimo no número de aloimunizações, é importante continuar as pesquisas em torno desse assunto na tentativa de diminuir os casos, visto que, se não tratada, a DHRN é letal.

Palavras-chave: Aloanticorpo. DHRN. Anemia. Recém-nascido.

\begin{abstract}
The Hemolytic Disease of the Newborn (HDN) is a hemolytic anemia caused by maternal-fetal blood incompatibility that can be triggered by various blood systems alloimmunization. The main ones are the $\mathrm{ABO}$ and $\mathrm{RH}$ systems. In this research, we performed a retrospective analysis of medical records of 3,080 newborns attended by Hemoclínica for the period of January to June, 2013. The results showed $4.83 \%$ of newborns had positive direct antiglobulin test whereas 2,68\% tested positive for Irregular Antibody Screening. In this total, 75,33\% of the cases were related to the $\mathrm{ABO}$ system and $6.67 \%$ to the Rh system. One association between $\mathrm{ABO}$ and $\mathrm{Rh}$ systems was found and also an antiFya. Despite advances in detection techniques of alloantibodies and immunoprophylaxis for the Rh system have led to a decrease in the number of alloimmunization, it is important to continue research around this issue in an attempt to reduce cases because, if left untreated, HDN is lethal.
\end{abstract}

Keywords: Alloantibody. HDN. Anemia. Newborn.
Recebido em: 02/06/14 Aprovado em: 13/10/14

1 Graduanda do curso de Biomedicina no UniCEUB, Brasília-DF.

2 Biomédico, mestre em Patologia Molecular, doutorando em Ciências Médicas na UnB, professor de Hematologia e Hemoterapia do UniCEUB, Brasília- DF. 


\section{Introdução}

Dentre os 29 sistemas sanguíneos hoje reconhecidos, os sistemas ABO e Rh são os de maior importância clínica devido à complexidade e imunogenicidade (LAGE; CABRAL; LEITE, 2006; BAIOCHI; NARDOZZA, 2009). O sistema sanguíneo $\mathrm{ABO}$ é determinado geneticamente por genes que ocupam o locus $\mathrm{ABH}$ no braço longo do cromossomo 9q34.1 e codificam glicosiltransferases capazes de adicionar carboidratos à substância precursora nas hemácias, dando origem aos antígenos A, B e H (GIRELLO; KÜHN, 2002). Estes podem estar presentes na membrana dos glóbulos vermelhos e em demais órgãos e líquidos orgânicos (DUEÑAS, 2003).

$\mathrm{O}$ sistema $\mathrm{ABO}$ também apresenta anticorpos regulares, completos e naturais (anti-A e anti-B) da classe IgM, os quais resultam da sensibilização com proteínas de bactérias semelhantes aos açúcares expressos nos antígenos A e B, que aparecem por volta de três meses após o nascimento e vão declinando com a idade (RUIZ, 2008; MATTOS; MOREIRA, 2004).

O sistema Rh é o mais complexo por possuir cerca de 48 antígenos que são codificados em diversas localizações cromossômicas (CASTILHO, 2007). Os genes desse sistema codificam proteínas que serão adicionadas à substância precursora nos eritrócitos e só estão presentes na membrana dessas células. $\mathrm{O}$ antígeno $\mathrm{RhD}$ é o de maior importância clínica devido à sua imunogenicidade e a sua presença ou ausência caracteriza os indivíduos como Rh positivo ou negativo, respectivamente (NARDOZZA et al., 2010).

Os anticorpos anti-Rh, diferentemente do que ocorre no sistema $\mathrm{ABO}$, só são produzidos após imunização passiva (autoimunização) ou ativa (aloimunização). Por se tratar de isoaglutininas, em sua maioria da classe IgG, precisam passar por um primeiro contato com o antígeno para que ocorra a sensibilização e, depois, num próximo contato poderá ocorrer a isoimunização (BATISTETI et al., 2007; CASTILHO, 2007).

A aloimunização (ou isoimunização) é um processo de produção de anticorpos decorrente da exposição do indivíduo a antígenos não próprios e pode ocorrer no caso de uma gravidez ou transfusões incompatíveis (BAIOCHI; NARDOZZA, 2009). Ao ocorrer durante a gravidez, leva à hemólise fetal, condição chamada de Doença Hemolítica do Recém-Nascido (DHRN), que tem como causa principal a incompatibilidade causada pelos sistemas ABO e Rh. Essa condição pode apresentar sinais como a icterícia, hepatoesplenomegalia, anemia fetal em diferentes graus e, até mesmo, óbito (MACHADO; BARINI, 2006).
A isoimunização do sistema $\mathrm{ABO}$ ocorre na gravidez quando a mãe possui o tipo sanguíneo $\mathrm{O}$ e tem filho A e/ou B. A mãe, que possui anticorpos anti-A e anti-B da classe IgM, quando entra em contato com um número suficiente de eritrócitos fetais na sua circulação, desencadeia uma resposta imune com produção maciça de anticorpos IgG (CUNNINGHAM et al., 2012; MALONO et al., 2013). Esses anticorpos, por possuírem peso molecular mais baixo que os do tipo IgM, são capazes de atravessar a barreira placentária e podem levar à hemólise fetal no primeiro filho (MALONO et al., 2013).

No caso do sistema Rh, a isoimunização passiva ocorrerá após uma primeira gravidez em que uma quantidade suficiente de sangue Rh positivo do feto entre na corrente sanguínea da mãe Rh negativa, estimulando uma sensibilização com produção de anticorpos anti-Rh. Em uma segunda gravidez, em que o feto seja novamente Rh positivo, esses aloanticorpos anti-Rh (maioria de classe IgG) atravessarão a barreira placentária e levarão à hemólise fetal (LEVINE, 1943).

A DHRN, causada pela isoimunização $\mathrm{ABO}$, normalmente leva a um quadro clínico com sintomas e evolução menos acentuados que a incompatibilidade causada pelo sistema $\mathrm{Rh}$, porém, pode haver a necessidade de terapêutica com imunoglobulina ou, em casos excepcionais, com exsanguíneo-transfusão para ambos os casos (MALONO et al., 2013). Por isso a importância de fechar o diagnóstico com a pesquisa dos anticorpos antieritrocitários na corrente sanguínea fetal (CIANCIARULLO; CECCON; VAZ, 2003).

A detecção desses aloanticorpos é feita por métodos como: Teste de Antiglobulina Direta (TAD), para pesquisa de anticorpos fixados sobre as hemácias; Pesquisa de Anticorpos Irregulares (PAI), para pesquisa de anticorpos no soro; Teste de Coombs Monoespecífico, para pesquisa de IgG; e Eluição, que consiste em remover os anticorpos da membrana da hemácia para posterior identificação (RUIZ, 2013).

Esta pesquisa teve como objetivo fazer um levantamento da frequência dos anticorpos $\mathrm{ABO}$ e $\mathrm{Rh}$ maternos em recém-nascidos de hospitais particulares do Distrito Federal por meio da análise retrospectiva de prontuários da Hemoclínica de Brasília.

\section{Metodologia}

Foi feito um estudo descritivo retrospectivo de análise de 3.080 prontuários de recém-nascidos do Distrito Federal 
que foram atendidos na Hemoclínica de Brasília no período de primeiro de janeiro de 2013 a 30 de junho de 2013 e tiveram positividade no Teste de Antiglobulina Direta e/ou Pesquisa de Anticorpos Irregulares. Os prontuários analisados referem-se a exames realizados pela Hemoclínica de Brasília e encontram-se armazenados em banco de dados informatizado da instituição. De cada prontuário, foram obtidas as seguintes informações: tipagem sanguínea $\mathrm{ABO}$ e $\mathrm{Rh}$ do recém-nascido, resultado do TAD, resultado do PAI, resultado do eluato e painel de hemácias. Utilizou-se a porcentagem como ferramenta de análise de dados. Para o presente trabalho, foi solicitada a dispensa do Termo de Consentimento Livre e Esclarecido por não envolver o sujeito de pesquisa, e sim a utilização de informação de banco de dados.

O presente projeto foi aprovado pelo Comitê de Ética em Pesquisa do UniCEUB sob o parecer № 422.310/2013 e seguiu as normas recomendadas pela Legislação Brasileira de Pesquisa envolvendo seres humanos, conforme Resolução No 196/96 do Conselho Nacional de Saúde.

\section{Resultados}

Do total de 3.080 recém-nascidos atendidos, 149 (4,83\%) tiveram positividade no Teste de Antiglobulina Direto (TAD) e destes, 4 (2,68\%) tiveram positividade na Pesquisa de Anticorpos Irregulares (PAI). Dentre os que tiveram TAD positivo, 7 (4,70\%) possuíam o anticorpo anti-D, 2 (1,34\%) anti-c, 78 (52,35\%) anti-A, 21 (14,09\%) anti-B, 1 (0,67\%) anti-Fy ${ }^{\mathrm{a}}, 1(0,67 \%)$ possuía a associação de anti-D + anti-C + anti-A, 13 (8,73\%) possuíam a associação de anti-A + anti-B e $26(17,45 \%)$ obtiveram resultado negativo no eluato, como demonstrado na Tabela 1.

No conjunto dos que possuíam TAD positivo, 4 (2,68\%) também apresentaram PAI positivo. Eles se encontravam da seguinte forma: 1 (25\%) possuía anti-Fya no soro com mãe positiva para anti-Fya; 1 (25\%) possuía anti-c no soro com mãe positiva para anti-c; 2 (50\%) possuíam anti-D no soro com mãe positiva para anti-D e, em um deles, a mãe tomou a imunoglobulina anti-IgG humana $(\mathrm{Rh}(\mathrm{o})$ gam). Além desses, dois resultados foram considerados duvidosos quanto à positividade no PAI. Nos prontuários em questão, havia o relato de anticorpos no soro, mas não havia nenhum resultado descrito no campo do PAI e nenhuma outra observação quanto à realização ou não do teste para confirmar sua positividade. Considerando-se esses dois prontuários que constavam de anticorpos no soro, as porcentagens mudam como é demonstrado na Tabela 2.
Tabela 1- Anticorpos encontrados nos pacientes que obtiveram TAD positivo.

\begin{tabular}{|c|c|c|}
\hline TIPO DE ANTICORPO & $n^{\circ}$ & $\%$ \\
\hline \multicolumn{3}{|l|}{ Sistema Rh } \\
\hline anti-D & 7 & 4,70 \\
\hline anti-c & 2 & 1,34 \\
\hline \multicolumn{3}{|l|}{ Sistema ABO } \\
\hline anti-A & 78 & 52,35 \\
\hline anti-B & 21 & 14,09 \\
\hline \multicolumn{3}{|l|}{ Outros sistemas } \\
\hline anti-Fy (Duffy) & 1 & 0,67 \\
\hline \multicolumn{3}{|l|}{ Associações } \\
\hline anti-D + anti-C + anti-A & 1 & 0,67 \\
\hline anti-A + anti-B & 13 & 8,73 \\
\hline Negativo & 26 & 17,45 \\
\hline Total & 149 & 100 \\
\hline
\end{tabular}

Tabela 2 - Anticorpos encontrados nos pacientes com PAI positivo.

\begin{tabular}{|l|c|c|}
\hline TIPO DE ANTICORPO & $\mathbf{n}^{\mathbf{0}}$ & $\%$ \\
\hline Sistema Rh & & \\
\hline \multicolumn{1}{|c|}{ anti-D } \\
anti-c
\end{tabular}

De todos os recém-nascidos que tiveram TAD e/ou PAI positivos, 90 (60,40\%) são do tipo sanguíneo A Rh positivo e 8 (5,36\%) A Rh negativo; 37 (24,83\%) B Rh positivo e $1(0,67 \%)$ B Rh negativo; 2 (1,34\%) são $A B$ Rh positivo; 10 (6,71\%) são O Rh positivo e 1 (0,67\%) O Rh negativo. Apenas dois (1,34\%) dos recém-nascidos que tiveram suspeita de imunização passiva com TAD e/ou PAI positivos necessitaram de transfusão sanguínea para tratar a anemia e possuíram incompatibilidade pelo sistema $\mathrm{ABO}$.

Em relação ao percentual de aloimunizações por sistemas sanguíneos, foram encontrados 113 (75,33\%) casos relacionados com o sistema ABO; 10 (6,67\%) com o sistema Rh; 1 (0,67\%) correspondente ao sistema Duffy; e, o restante, 26 (17,33\%), não teve anticorpos dos sistemas sanguíneos identificados na amostra. Foi observado que um dos casos teve a associação entre os sistemas $\mathrm{ABO}$ e Rh, 
razão pela qual a totalidade dos casos ultrapassa 149, como demonstrado no Gráfico 1. Somados, os sistemas ABO e Rh correspondem a $82 \%$ dos casos de aloimunização.

Gráfico 1: Análise de aloimunizações por sistema sanguíneo.

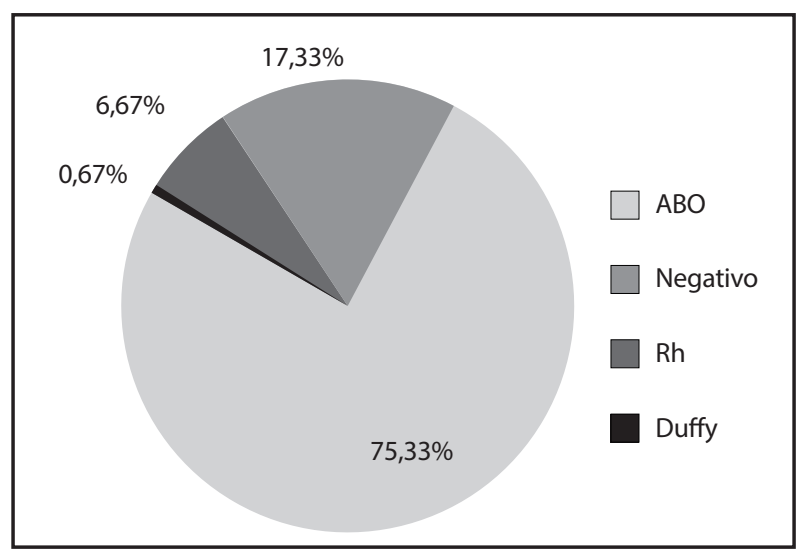

\section{Discussão}

A aloimunização, produção de anticorpos a partir do contato com antígenos não próprios, pode ser decorrente de transfusão sanguínea ou gravidez incompatível (GIRELLO; KÜHN, 2002). Ao ocorrer na gravidez, pode levar à Doença Hemolítica do recém-nascido (DHRN), uma anemia hemolítica causada devido à passagem de anticorpos IgG maternos antieritrocitários para o feto pela barreira placentária (GUYTON; HALL, 1998). Para detectar esses anticorde Hemácias (RUIZ, 2013).

No presente estudo, foi possível levantar a frequência desse evento e demonstrar que, durante o período analisado, apenas 4,83\% dos recém-nascidos sofreram aloimunização e, ainda, poucos evoluíram para uma forma grave da doença. Pesquisas realizadas com gestantes que haviam produzido isoaglutininas antieritrocitárias comprovaram que não se espera que esse número seja alto, conforme mostra o estudo de Cianciarullo, Ceccon e Vaz (2003) que descreveu que apenas 9\% das gestantes haviam sido aloimunizadas.

A incompatibilidade materno-fetal pode ocorrer com diversos sistemas sanguíneos, porém os principais causadores são os sistemas ABO e Rh. No trabalho em questão, esses sistemas corresponderam, em separado ou associados, a um total de $82 \%$ dos casos. A incompatibilidade do sistema $\mathrm{ABO}$ é a mais frequente, ocorrendo em cerca de 20 a 25\% das gestações (LAGE; CABRAL; LEITE, 2006). Em concordância com o achado no estudo teórico, a aloimunizão pelo sistema $\mathrm{ABO}$ foi a mais prevalente, correspondendo a 75,33\% dos casos analisados. Destes, apenas dois casos (1,73\%) desenvolveram uma anemia significativa e precisaram de transfusão.

Em contrapartida, a literatura apresenta que a incompatibilidade do sistema Rh ocorre em cerca de 10\% das gestações e é responsável por 95\% dos casos de DHRN, sendo, portanto, a mais grave e preocupante (MALONO et al., 2013; BAIOCHI et al., 2004). Nos materiais analisados, $6,67 \%$ dos recém-nascidos aloimunizados tinham incompatibilidade pelo sistema $\mathrm{Rh}$, porém, nenhum evoluiu para anemia grave. Esse número baixo deve-se também à profilaxia realizada com as gestantes que são $\mathrm{Rh}$ negativo com o uso da imunoglobulina anti-IgG humana no intuito de impedir a sensibilização da mãe contra o antígeno D do feto (BAIOCHI; NARDOZZA, 2009).

Foram encontrados anticorpos do sistema Rh contra antígenos menos imunogênicos que o $\mathrm{D}$, mas que também podem levar à isoimunização como o anti-C e anti-c. Eles aparecem com menos frequência, porém podem, dependendo da hemólise causada no feto, resultar em um quadro grave (MONTEIRO et al., 1996).

Dentre os anticorpos irregulares que podem levar à DHRN, em segundo lugar de frequência e importância clínica estão os sistemas Duffy e Kell (KORNSTAD, 1983). Do sistema Duffy, foi encontrado um anticorpo anti-Fy, que, como demonstrado na literatura, é o mais frequente e de maior imunogenicidade dentro desse sistema, podendo levar à anemia fetal (JENS; PAGLIARINI; NOVARETTI, 2005). O caso encontrado em nossa pesquisa não evoluiu para a forma grave e não foi encontrado nenhum anticorpo do sistema Kell nas amostras analisadas.

Dos 149 que apresentaram TAD positivo, 4 geraram dúvida quanto à associação com a aloimunização passiva. Um deles é um caso do tipo sanguíneo A que apresentou no eluato o anticorpo anti-B, e os outros 3 são do tipo $\mathrm{O}$ e apresentaram no eluato o anti-A. Por se tratarem de anticorpos de ocorrência natural e esperados para os tipos sanguíneos descritos, deixam um questionamento se houve uma produção precoce desses anticorpos ou se são resultado de uma isoimunização materno-fetal. Em um caso normal, a produção esperada para essas aglutininas seria apenas por volta dos três meses de vida (RUIZ et al., 2008).

Nos casos que tiveram positividade no TAD, $17,44 \%$ tiveram resultado negativo para a identificação de anticorpos dos sistemas sanguíneos na amostra, o que pode caracterizar reação cruzada com outros tipos 
de anticorpos ou positividade por proteínas do sistema complemento que estavam aderidas nas hemácias. De acordo com Girello e Kühn (2002), o TAD é um teste que pesquisa anticorpos ou frações do complemento fixados à hemácia. Portanto, essa positividade no TAD pode ter ocorrido pela detecção de um fragmento de proteína do complemento, até mesmo inativo (como o C3d), adsorvido na hemácia por um aloanticorpo ou autoanticorpo. $\mathrm{O}$ resultado do Eluato negativo pode ser explicado pela dissociação da imunoglobulina durante a lavagem do sangue ou até mesmo, por conter títulos abaixo do limiar de sensibilidade do teste, não sendo possível identificá-las (GIRELLO; KÜHN, 2002).

\section{Conclusão}

Como demonstrado neste trabalho a maior parte dos casos de aloimunização foi devido aos sistemas $\mathrm{ABO}$ e Rh. Nas últimas décadas, houve um decréscimo na mortalidade perinatal decorrente da DHRN por aloimunização materna. Isso se deve aos avanços nas técnicas de detecção desses anticorpos e na implementação de programas de atenção pré-natal. O uso da imunoglobulina anti-IgG humana como imunoprofilaxia fez com que a incidência da isoimunização $\mathrm{Rh}$ diminuísse consideravelmente, em contrapartida, a atenção se voltou para a incompatibilidade por outros sistemas sanguíneos.

Entretanto, apesar do decréscimo na mortalidade e a porcentagem baixa de casos de aloimunização, deve-se continuar tentando antever os casos de incompatibilidade materno-fetal referente aos diversos tipos sanguíneos para evitar a DHRN visto que, quando não tratada, tem alta letalidade.

\section{Referências}

BAIOCHI, E.; NARDOZZA, L. M. M. Aloimunização. Revista Brasileira de Ginecologia e Obstetrícia, Rio de Janeiro, v. 31, n. 6, p. 311-319, jun. 2009. doi: $10.1590 /$ S0100-72032009000600008

BAIOCHI, E. et al. Porque usamos imunoglobulina anti-D em excesso no abortamento precoce? Revista Brasileira de Ginecologia e Obstetrícia, Rio de Janeiro, v. 26 , n. 5 , p. $363-367$, jun. 2004 . doi: $10.1590 /$ S010072032004000500004

BATISTETI, C. B. et al. O sistema de grupo sanguíneo Rh. Filosofia e História da Biologia, São Paulo, v. 2, p. 85-101, jan./dez. 2007.
CASTILHO, L. Sistema de grupo sanguíneo Rh. In: BORDIN, J. O.; LANGHI JÚNIOR, D. M.; COVAS, D. T. Hemoterapia: fundamentos e prática. São Paulo: Atheneu, 2007. p. 138-144.

CIANCIARUlLO, M. A.; CECCON, M. E. J.; VAZ, F. A. C. Prevalência de marcadores imuno-hematológicos em recém-nascidos ao nascimento e em suas respectivas mães e incidência de doença hemolítica numa maternidade de São Paulo. Revista da Associação Médica Brasileira, São Paulo, v. 49, n. 1, p. 45-53, jan./mar. 2003. doi: $10.1590 /$ S0104-42302003000100033

CUNNINGHAM, K. L. et al. Obstetrícia de Williams. 23. ed. São Paulo: AMGH, 2012.

DUEÑAS, V. H. El banco de sangre: teoría, principio y procedimientos. 2. ed. Cali, Colombia: Universidad Del Valle, 2003.

GUYTON, MD, A. C.; HALL, J. E. Fisiologia humana e mecanismos das doenças. 6. ed. Rio de Janeiro: Guanabara Koogan, 1998.

GIRELLO, A. L.; KÜHN, T. I. B. B. Fundamentos da imuno-hematologia eritrocitária. São Paulo: Senac, 2002.

JENS, E.; PAGLIARINI, T.; NOVARETTI, M. C. Z. Sistema de grupo sangüíneo Duffy: biologia e prática transfusional. Revista Brasileira de Hematologia e Hemoterapia, São José do Rio Preto, v. 27, n. 2, p. 110-119, abr./ jun. 2005. doi: 10.1590/S1516-84842005000200011

KORNSTAD, L. New cases of irregular blood group antibodies other than anti-D in pregnancy: frequency and clinical significance. Acta Obstetricia et Gynecologica Scandinavica, Escandinávia, v. 62, n. 5, p. 431-436, May 1983. doi:10.3109/00016348309154215

LAGE, E. M.; CABRAL, A. C. V.; LEITE, H. V. Fluxo no ducto venoso e na veia cava inferior dos fetos em gestações isoimunizadas. Revista da Associação Médica Brasileira, São Paulo, v. 52, n. 5, p. 328-332, set./out. 2006. doi: 10.1590/S0104-42302006000500020

LEVINE, P. Serological factors as possible causes in spontaneous abortions. The Journal of Heredity, Oxford, v. 34, n. 3, p. 71-80, mar. 1943.

MACHADO, I. N.; BARINI, R. Doença hemoítica perinatal: aspectos atuais. Revista de Ciências Médicas, Campinas, v. 15, n. 1, p. 69-74, jan./fev. 2006.

MALONO, J. et al. Doença hemolítica do recém-nascido. Secção de Neonatologia SPP. Disponível em: < http://www. lusoneonatologia.com/site/upload/File/Doença\%20hemolitica\%20do\%20RN.pdf>. Acesso em: 8 maio 2013. 
MATTOS, L. C.; MOREIRA, H. W. Genetic of the ABO blood system and its link with the immune system. Revista Brasileira de Hematologia e Hemoterapia, São José do Rio Preto, v. 26, n. 1, mar. 2004. doi: 10.1590/ S1516-84842004000100012

MONTEIRO, M. A. G. et al. Aspectos imuno-hematológicos, genéticos e clínicos da aloimunização por anticorpo anti-c: relato de dois casos. Pediatria (São Paulo), São Paulo, v. 18, n. 2, p. 95-98, abr./jun. 1996.

NARDOZZA, L. M. M. et al. Bases moleculares do sistema $\mathrm{Rh}$ e suas aplicações em obstetrícia e medicina transfusional. Revista da Associação Médica Brasileira, São Paulo, v. 56, n. 6, p. 724-728, nov./dez. 2010. doi: $10.1590 /$ S0104-42302010000600026

RUIZ, L. G. P. Frequência de aloanticorpos e auto-anticorpos em pacientes politransfundidos atendidos pelo Hemonúcleo de Catanduva (Hemorede-Funfarme). Revista do Biomédico. 67. ed. Disponível em: <http://www.crbm1. com.br/bio67/artigocien_67.asp> Acesso em: 8 maio 2013.
RUIZ, L. G. P. et al. Detecção dos anticorpos regulares abo maternos em recém-nascidos pelo método de tipagem sanguínea reversa estendida até fase de antiglobulina humana. Revista Brasileira de Análises Clínicas, Rio de Janeiro, v. 40, n. 4, p. 301-303, out./dez. 2008.

\section{Agradecimentos}

Agradeço ao meu orientador, professor Msc. Milton Rego de Paula Junior, por acreditar em mim, pela paciência e perseverança com a nossa pesquisa. A todos da Hemoclínica que me receberam com muito carinho e tornaram possível a conclusão deste trabalho, em especial, ao Charlles Alexandre da Silva que esteve presente e disposto a ajudar durante todo o processo. Ao Biomédico Erich Hartmann, que me indicou caminhos para iniciar a pesquisa. 